\title{
Transition of care at discharge from the Intensive Care Unit: a scoping review*
}

\author{
Michele Elisa Weschenfelder Hervé ${ }^{1,2}$ \\ (D) https://orcid.org/0000-0002-5622-7680 \\ Paula Buchs Zucatti ${ }^{1,3}$ \\ (D) https://orcid.org/0000-0003-0406-6835 \\ Maria Alice Dias Da Silva Lima ${ }^{1}$ \\ (DD https://orcid.org/0000-0002-3490-7335
}

\footnotetext{
* Paper extracted from master's thesis "Associação da Transição do Cuidado com Eventos Adversos após a Alta de um Centro de Terapia Intensiva", presented to Universidade Federal do Rio Grande do Sul, Porto Alegre, RS. Supported by Conselho Nacional de Desenvolvimento Científico e Tecnológico (CNPq), Brazil, Grant \# 4339972018-4.

1 Universidade Federal do Rio Grande do Sul, Porto Alegre, RS, Brazil.

2 Hospital de Clínicas de Porto Alegre, Centro de Terapia Intensiva, Porto Alegre, RS, Brazil.

${ }^{3}$ Hospital Conceição, Unidade de Terapia Intensiva, Porto Alegre, RS, Brazil.
}

Objective: to map the available evidence on the components of the transition of care, practices, strategies, and tools used in the discharge from the Intensive Care Unit (ICU) to the Inpatient Unit (IU) and its impact on the outcomes of adult patients. Method: a scoping review using search strategies in six relevant health databases. Results: 37 articles were included, in which 30 practices, strategies or tools were identified for organizing and executing the transfer process, with positive or negative impacts, related to factors intrinsic to the Intensive Care Unit and the Inpatient Unit and crosssectional factors regarding the staff. The analysis of hospital readmission and mortality outcomes was prevalent in the included studies, in which trends and potential protective actions for a successful care transition are found; however, they still lack more robust evidence and consensus in the literature. Conclusion: transition of care components and practices were identified, in addition to factors intrinsic to the patient, associated with worse outcomes after discharge from the Intensive Care Unit. Discharges at night or on weekends were associated with increased rates of readmission and mortality; however, the association of other practices with the patient's outcome is still inconclusive.

Descriptors: Critical Care; Intensive Care Units; Patient Transfer; Continuity of Patient Care; Patient Discharge; Patient Handoff.

\section{How to cite this article}

Hervé MEW, Zucatti PB, Lima MADS. Transition of care at discharge from the Intensive Care Unit: A scoping review. Rev. Latino-Am. Enfermagem. 2020;28:e3325. [Access DOI: http://dx.doi.org/10.1590/1518-8345.4008.3325.

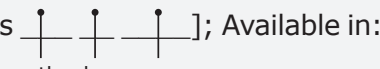

month day year

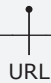




\section{Introduction}

Transition of care refers to a set of actions aimed at the coordination and continuity of care in the transfer of patients between different locations in the health system, or between different levels of care within the same institution ${ }^{(1)}$. The quality of transition of care is used as one of the components for evaluating the performance of hospitals by the World Health Organization (WHO) and by the Joint Commission International (JCI), and is related to the International Patient Safety Goal 2 - Communication ${ }^{(1-2)}$

It is a complex process involving several elements and stages, such as effective communication, patient and family guidance, responsibility of each of the parties involved, discharge planning, and knowledge about the resources and structure of the destination scenario, among others ${ }^{(1,3)}$. Therefore, the process is extremely vulnerable to the loss of critical information and to failures in the continuity of care. An inadequate transition of care can lead to serious adverse events, omission of care, duplication of care, delays in treatment, receiving inadequate treatment, increased morbidity and mortality, in addition to dissatisfaction of the patient, family and professionals, the inadequate use of health services and increased $\operatorname{costs}^{(2)}$.

The transition of care from the Intensive Care Unit (ICU) to the Inpatient Unit (IU) is related to an even higher risk due to a combination of factors such as the severity of the patients, multiple comorbidities and complexity of the care, change from an environment with many monitoring resources to an environment with fewer resources, number and complexity of the professionals involved (multidisciplinary and interspecialties), lack of transition programs or lack of standardization of the discharge process, in addition to frequent oral and written miscommunication between the staff and between professionals and the patient/ family(4-7). Despite the growing knowledge on the subject, the quality of transition practices is still very varied, with deficits in planning, coordination of care and exchange of information between ICU and IU health professionals ${ }^{(7)}$.

The occurrence of adverse events after discharge from the ICU is related to events with medication, falls and nosocomial infection, clinical deterioration, cardiorespiratory arrest, readmission and death( ${ }^{(8-11)}$. However, studies that assess the occurrence of other outcomes are still scarce; and most focus only on readmission and death rates ${ }^{(6,12-14)}$. The association between the occurrence of such events and the poor quality of the transition of care is demonstrated in some studies; however, the literature is still controversial on the topic ${ }^{(4,13-14)}$.
The adoption of standardized and precise guidelines is important to determine the ideal time for discharge, as well as to predict patients at greatest risk of suffering adverse events after the transfer. However, risk factors and discharge criteria are not clearly defined( $8,10-11,15)$. Although guidelines and transition programs are considered effective management tools to reduce length of stay and improve use of resource, few institutions have a policy regarding transition of care or written guidelines for the discharge process from the $\operatorname{ICU}(4,15)$.

A scoping review conducted in $2015^{(4)}$ about patients discharged from the ICU to inpatient units analyzed studies published until 2013, without age or clinical profile restrictions, including adult, pediatric, and neonatal patients. The results indicated components or stages for an ICU discharge strategy, such as institutional guidelines to standardize the processes regarding transition of care, risk stratification of patients, training of professionals and adoption of a discharge plan. In addition, determining the best day and time for discharge, reducing transfer delays, oral communication between providers, a verification checklist before transfer, patient follow-up, and evaluation of post-discharge outcomes are also mentioned as important elements ${ }^{(4)}$. The gap in the review ${ }^{(4)}$ is the need to assess the elements identified, adapted to local needs and contexts before widespread implementation ${ }^{(4)}$. The association between different discharge practices and patient outcomes was also not assessed.

Thus, this study intends to map the available evidence on the components of the transition of care, the practices, strategies and tools used in the discharge of patients from the ICU to the IU and the impact on the outcomes of adult patients.

\section{Method}

The knowledge synthesis method adopted was the scoping review(16). The following phases were developed according to the methodology proposed by the Joanna Briggs Institute ${ }^{(17)}$ : definition and alignment of research objectives and questions; establishing inclusion criteria according to the objectives and questions; elaboration and planning of the study search and selection strategy; identification of relevant studies; selection of studies; data extraction; data mapping; and summarizing the results.

This investigation was guided by the following questions: What are the components of the transition of patients from ICU to IU according to the literature? What practices, strategies, and tools are associated with improving the quality of discharge from the ICU to the IU? What is its impact on patients' outcomes after the transfer? 
The inclusion criteria for the selection included the following: primary studies carried out with adult patients (18 years old or older); published in English, Spanish or Portuguese; and in the period from January $1^{\text {st }}, 2014$ to December $31^{\text {st }}, 2018$. The delimitation of this period is justified because there is already in the literature a scoping review on the topic that included studies until $2013^{(4)}$.

Duplicate articles, those that did not answer at least one of the research questions, review studies, books, letters to the editor, abstracts published in annals and studies about patients transferred from the ICU for psychiatric, obstetric or palliative care were excluded, due to the particularities in the care of these patients and because they are frequently transferred to specialized inpatient units, limiting the comparison of results.

The search strategy consisted of three stages: i) Initial research in the PubMed and Cumulative Index to Nursing and Allied Health Literature (CINAHL) databases using the descriptors found in the Medical Subject Headings (MeSH): critical care, intensive care unit, patient transfer, continuity of patient care, patient handoff, patient handover, patient care team, communication, patient discharge, patient readmission, followed by an analysis of the keywords contained in the title, summary and descriptors of the articles, identifying uncontrolled descriptors: care transitions, discharge practices and discharge planning; ii) Second search using all the descriptors identified in the included databases -PubMed, CINAHL, Latin American and Caribbean Health Sciences Literature (Literatura LatinoAmericana e do Caribe em Ciências da Saúde, LILACS), Web of Science, Scopus, and Embase. The boolean operators OR and AND were used, as shown in Figure 1; iii) A search was carried out in the references of the included articles in order to track additional studies not identified by the search strategies. The study selection process, as well as the last search, took place in April and May 2019.

The selected references were sent to the Mendeley ${ }^{\circledR}$ bibliographic managing software. Two researchers worked independently to select the studies by title,

\begin{tabular}{|c|c|c|}
\hline Database & Strategy & Limiters \\
\hline PubMed & 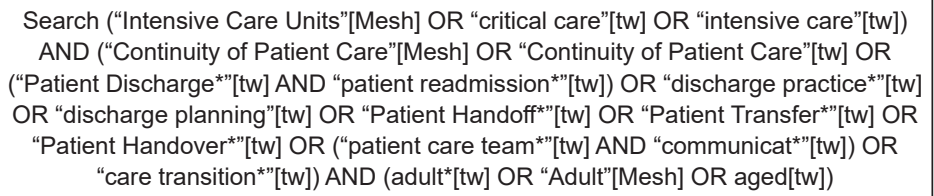 & $\begin{array}{l}\text { Journal Article; published in the last } 5 \text { years; } \\
\text { Humans; English; Portuguese; Spanish }\end{array}$ \\
\hline CINAHL & 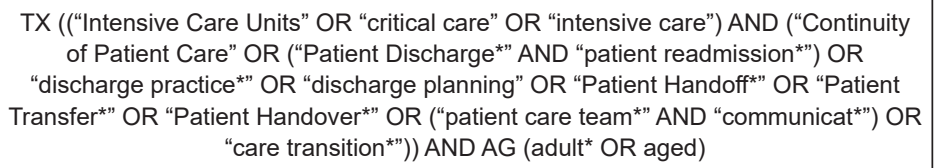 & $\begin{array}{l}\text { Publication date: 20130101-20181231; } \\
\text { Language: English, Portuguese, Spanish }\end{array}$ \\
\hline LILACS & 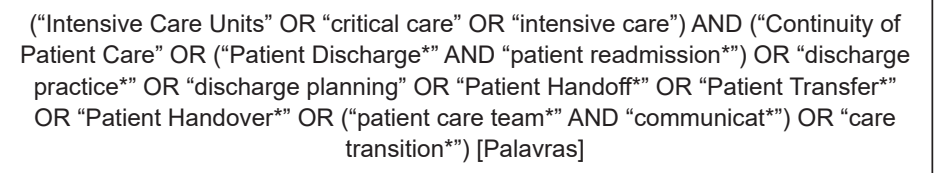 & $\begin{array}{l}2013 \text { OR } 2014 \text { OR } 2015 \text { OR } 2016 \text { OR } 2017 \\
\text { OR } 2018 \text { [Country, year of publication] }\end{array}$ \\
\hline Web of Science & 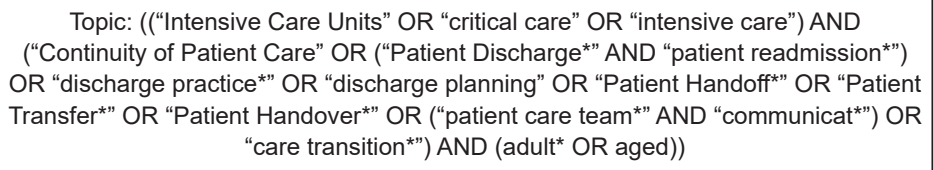 & $\begin{array}{c}\text { Years of the publication: (2018 OR } 2017 \\
\text { OR } 2016 \text { OR } 2015 \text { OR } 2014 \text { OR 2013) AND } \\
\text { Languages: (ENGLISH OR PORTUGUESE } \\
\text { OR SPANISH) }\end{array}$ \\
\hline Scopus & $\begin{array}{l}\text { TITLE-ABS-KEY (“Intensive Care Units" OR "critical care" OR "intensive care") AND } \\
\text { TITLE-ABS-KEY (“Continuity of Patient Care" OR (“Patient Discharge" AND "patient } \\
\text { readmission*”) OR "discharge practice*” OR "discharge planning" OR "Patient } \\
\text { Handoff*" OR "Patient Transfer*” OR "Patient Handover" OR ("patient care team"” } \\
\text { AND "communicat"”) OR “care transition") AND TITLE-ABS-KEY (adult" OR aged) }\end{array}$ & $\begin{array}{l}\text { (LIMIT-TO (PUBYEAR, 2018) OR } \\
\text { LIMIT-TO (PUBYEAR, 2017) OR LIMIT- } \\
\text { TO (PUBYEAR, 2016) OR LIMIT-TO } \\
\text { (PUBYEAR, 2015) OR LIMIT-TO } \\
\text { (PUBYEAR, 2014) OR LIMIT-TO } \\
\text { (PUBYEAR, 2013)) AND (LIMIT-TO } \\
\text { (LANGUAGE, "English") OR LIMIT-TO } \\
\text { (LANGUAGE, "Spanish") OR LIMIT-TO } \\
\text { (LANGUAGE, "Portuguese")) }\end{array}$ \\
\hline Embase & $\begin{array}{c}\text { All fields ('intensive care' OR 'intensive care unit') AND ('patient transfer' OR } \\
\text { ('patient care' AND 'interpersonal communication') OR 'clinical handover' OR 'care } \\
\text { transition') AND ([adult]/lim OR [aged]/lim OR [middle aged]/lim OR [very elderly]/lim } \\
\text { OR [young adult]/lim) }\end{array}$ & $\begin{array}{l}\text { (2013:py OR 2014:py OR 2015:py OR } \\
\text { 2016:py OR 2017:py OR 2018:py) AND } \\
\text { ([english]/lim OR [portuguese]/lim OR } \\
\text { [spanish]/lim) }\end{array}$ \\
\hline
\end{tabular}

Figure 1 - Database search strategy using boolean operators. Porto Alegre, RS, Brazil, 2019 
abstract, and full text. The two reviewers evaluated the full versions of the text of the selected articles, considering the inclusion and exclusion criteria, resulting in the final study sample. In each phase, a consensus was reached between the reviewers through discussion.

The researchers prepared a data extraction form to record the characteristics of the included studies and the main information relevant to the research, containing the following sections: author(s), title, journal, country, year, volume, number, objective(s), population, sample size, method, how the results were measured, main findings, and study category. The impact of the transition of care practices, strategies or tools was interpreted as positive or negative, through the researchers' consensus after extracting the results independently, according to the effect on the quality of the transition of care, its implementation, and the conclusion of its stages and/or according to the association with the patients' outcomes.

\section{Results}

The search in the databases identified 2,124 potentially eligible studies and another four articles were selected from the references, 37 remaining in the final sample, as shown in Figure 2.

The characteristics of the articles are summarized in Table 1. The research studies were carried out mainly in the United States, Canada, and Australia, and the methodology was quite varied, with a bigger number of qualitative, cohort, and quasi-experimental studies.

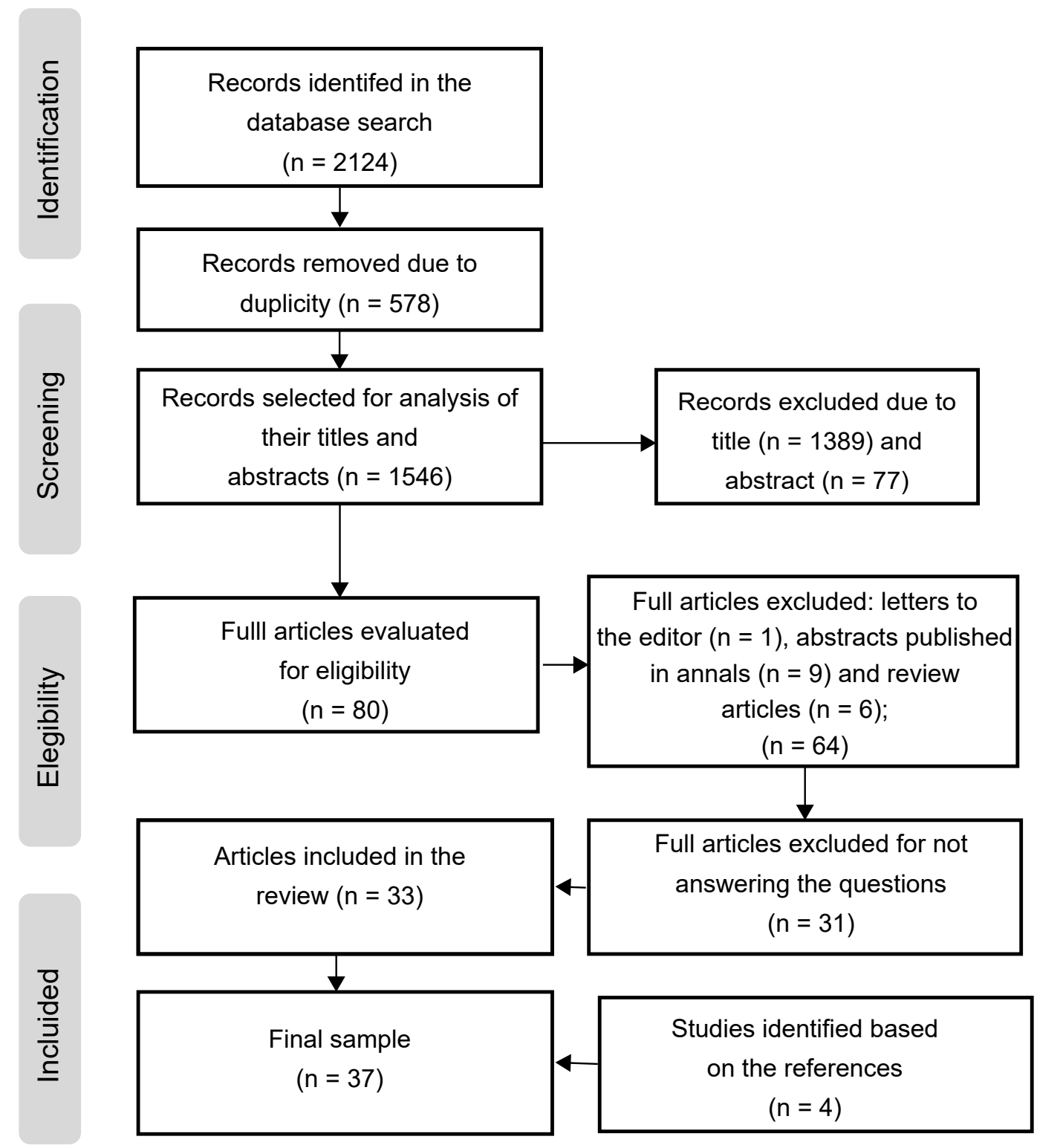

Figure 2 - Flowchart of the study selection process adapted from Preferred Reporting Items for Systematic Review and Meta-Analyses (PRISMA)(18). Porto Alegre, RS, Brazil, 2019 
Table 1 - Distribution of the included studies according to country, type of study, and year of publication. Porto Alegre, RS, Brazil, 2019

\begin{tabular}{|c|c|c|}
\hline Characteristics & $\mathbf{n}^{*}$ & $\%^{\dagger}$ \\
\hline \multicolumn{3}{|l|}{ Country } \\
\hline United States & 8 & 21.6 \\
\hline Canada & 6 & 16.2 \\
\hline Australia & 4 & 10.8 \\
\hline Australia/New Zealand & 3 & 8.1 \\
\hline Sweden & 3 & 8.1 \\
\hline United Kingdom & 3 & 8.1 \\
\hline Netherlands & 2 & 5.4 \\
\hline South Korea & 2 & 5.4 \\
\hline Brazil & 1 & 2.7 \\
\hline Argentina & 1 & 2.7 \\
\hline Uruguay & 1 & 2.7 \\
\hline Norway & 1 & 2.7 \\
\hline Belgium & 1 & 2.7 \\
\hline United States, Canada, and United Kingdom & 1 & 2.7 \\
\hline \multicolumn{3}{|l|}{ Type of study } \\
\hline Quasi-experimental & 7 & 18.9 \\
\hline Prospective cohort & 7 & 18.9 \\
\hline Qualitative & 7 & 18.9 \\
\hline Descriptive & 6 & 16.2 \\
\hline Retrospective cohort & 5 & 13.5 \\
\hline Mixed (qualitative + descriptive) & 2 & 5.4 \\
\hline Clinical validation & 1 & 2.7 \\
\hline Randomized clinical trial & 1 & 2.7 \\
\hline Pilot Randomized Clinical Trial & 1 & 2.7 \\
\hline \multicolumn{3}{|l|}{ Year of publication } \\
\hline 2014 & 9 & 24.3 \\
\hline 2015 & 7 & 18.9 \\
\hline 2016 & 4 & 10.8 \\
\hline 2017 & 8 & 21.6 \\
\hline 2018 & 9 & 24.3 \\
\hline
\end{tabular}

${ }^{*} \mathrm{n}=$ Number of articles; ${ }^{+}$Percentage of articles

The transition of care components presented in the studies are extremely varied, ranging from factors related to the patient ${ }^{(11,19-21)}$, going through the practices, strategies and tools used for the organization and execution of the transfer process ${ }^{(22-24)}$, to factors related to the unit to which the patient will be transferred ${ }^{(11,24)}$.

The factors related to the patient, identified in the primary studies, are severity of the disease(11,19-21), presence of comorbidities ${ }^{(11,19)}$, presence of tracheostomy, older age ${ }^{(19-20)}$, altered state of consciousness, need for greater use of supportive therapies in the ICU, longer ICU stay, need for dialysis, and clinical causes of admission ${ }^{(20)}$. They are evidenced as predisposing factors for worse outcomes of the patients after being discharged from the ICU, such as adverse events or readmissions, in the perception of the professionals involved(11,21), the association with the increase in readmission and mortality rates also being quantitatively

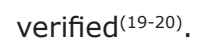

Some barriers are found for the continuity of care in the follow-up of the ICU, among these, the absence of specific discharge criteria and a feedback culture, the overestimation by the ICU team on the ability of the IU to monitor complex patients ${ }^{(25)}$, the change of health professionals, the changes in routines, and the substantial decrease in human resources and monitoring materials ${ }^{(13,21,24-25)}$.

On the other hand, several practices are identified as potential tools to improve the quality of transition of care and patient safety. One of the practices suggested is the adoption of a transfer checklist with items to check whether the patient is ready and the necessary adjustments before discharge, such as removal of invasive devices and medication reconciliation ${ }^{(23,26)}$. The oral or written communication was analyzed by several studies in different aspects. The use of a structured communication process using transfer of patients at bedside and standardized tools with multi-modal communication are strategies suggested(23,27).

The involvement and preparation of the family is presented as an essential stage in the discharge process, with individual assessment of the information needs, preparing the family to adjust to a different environment with less staff, technology and support ${ }^{(28)}$. A study that 
investigated family members' perceptions about the quality of care during the transfer process showed that the information about the transfer was significant for them, as they wanted to be part of the patient care and felt important when they had some vision and control over the necessary assistance. However, more than $20 \%$ felt that the information provided to them was inadequate ${ }^{(29)}$.

Another positive practice evidenced in the studies is being monitored or advised after discharge by members of the intensive care team. A qualitative study analyzing the perceptions of IU and ICU nurses on the benefits and challenges of the follow-up services of a post-intensive care group ${ }^{(30)}$ identified favorable points for both, such as the provision of additional care to the most vulnerable patients and continuity of intensive care, through periodic visits by the ICU team, in addition to the exchange of knowledge between the groups of nurses, in which the IU team's unpreparedness for more complex care was often identified. The impact of postdischarge follow-up programs was also quantitatively assessed, showing a decrease in hospital stay and in the ICU readmission rate ${ }^{(31)}$.

Figure 3 illustrates the synthesis of the main practices, strategies and tools presented in the studies, with a potential positive or negative impact on the quality of the transition of care and the patients' outcomes.

\begin{tabular}{|c|c|}
\hline $\begin{array}{l}\text { Practices, strategies and tools with potential positive or negative impact on the transition from the Intensive Care } \\
\text { Unit to the Inpatient Unit }\end{array}$ & Impact \\
\hline \multicolumn{2}{|l|}{ Factors related to the Intensive Care Unit } \\
\hline Discharge at night ${ }^{(11,21,24,32-35)}$, at shift changes ${ }^{(24)}$ and on weekends ${ }^{(19,21)}$ & Negative \\
\hline Inadequate and/or non-standard communication of key information (21,23-25,27,36-38) & Negative \\
\hline Premature discharge ${ }^{(11,20,28,77-38)}$ & Negative \\
\hline No discharge criteria ${ }^{(11,14,21,25,37)}$ & Negative \\
\hline Delays in the transfer(23-24,39-40) & Negative \\
\hline Undefined care goals ${ }^{(21,23-24,37)}$ & Negative \\
\hline Incorrect destination after discharge ${ }^{(1,22,38)}$ & Negative \\
\hline Inadequate environment for an efficient communication ${ }^{(21,23)}$ & Negative \\
\hline Ora|(14,22,27,41-44) and written ${ }^{(14,22,24,27-28,38,41,43,45)}$ communication with the inpatient unit staff & Positive \\
\hline Being monitored/advised by Intensive Care Unit professionals after discharge $\mathrm{e}^{(13-14,24-25,27,30-31,44,46-47)}$ & Positive \\
\hline Discharge planning and guidelines for patients/family(22-24,28-29,42,44-45,48) & Positive \\
\hline Medication reconciliation/review by the pharmacist ${ }^{(14,22,24-26,49)}$ & Positive \\
\hline Checklist/Transfer tools/Discharge protocols ${ }^{(22-23,25-27,41)}$ & Positive \\
\hline Anticipated discharge planning ${ }^{(14,25,29,44)}$ & Positive \\
\hline Participation of the patient and the family during the transfer ${ }^{(22,24,41-42)}$ & Positive \\
\hline Use of risk stratification tools/scores ${ }^{(23,43,50)}$ & Positive \\
\hline Transfer of care at the bedside ${ }^{(23-24,27)}$ & Positive \\
\hline Optimizing vital signs before discharge and reducing the need for intensive care ${ }^{(29,37)}$ & Positive \\
\hline Discharge to intermediate care units ${ }^{(14,50)}$ & Positive \\
\hline Institutional culture of valuing the transition of care process ${ }^{(27)}$ & Positive \\
\hline Transfer of care to their respective peers by all members of the multidisciplinary team ${ }^{(43)}$ & Positive \\
\hline \multicolumn{2}{|l|}{ Factors related to the Inpatient Unit } \\
\hline Lack of qualification and experience by the staff $(11,25,28,30,37-38,42)$ & Negative \\
\hline Reduced monitoring ${ }^{(11,14,34,37)}$ & Negative \\
\hline Reduced number of professionals ${ }^{(11,25,27,37)}$ & Negative \\
\hline Lack of available material resources ${ }^{(21,25,27)}$ & Negative \\
\hline Longer time until the first clinical evaluation of the patient ${ }^{(1,24,43)}$ & Negative \\
\hline Fragmentation of care in several teams ${ }^{(11)}$ & Negative \\
\hline Previous contact of the new team with the patient ${ }^{(24,29)}$ & Positive \\
\hline \multicolumn{2}{|l|}{ Factors related to the Intensive Care Unit and the Inpatient Unit } \\
\hline Accountability for information sent and received ${ }^{(23,29,43)}$ & Positive \\
\hline Readmission risk alert ${ }^{43,50)}$ & Positive \\
\hline
\end{tabular}

Figure 3 - Practices, strategies and tools with potential positive or negative impact on the transition from the ICU to the IU. Porto Alegre, RS, Brazil, 2019

The outcomes and adverse events analyzed are mostly focused on readmission ${ }^{(13-14,20,26,31-32,34-35,43,46-47,49-52)}$ and on mortality after discharge from the ICU(13-14,19-20,31$35,39,43,46,49,51-52)$. The mortality rate after discharge from the ICU varies from $3.0 \%^{(46)}$ to $30 \%^{(19)}$ according to the studies. Readmission affects $4.1 \%^{(51)}$ to $9.2 \%(46)$ of the patients in any period of hospitalization, $2.9 \%{ }^{(14)}$ in
48 hours after the transfer and $2.7 \%^{(32)}$ to $4.2 \%{ }^{(13)}$ within 72 hours. Other clinical outcomes analyzed are length of hospital stay(31-32,35,39-40,49), care provided by a Rapid Response Team (RRT) ${ }^{(26,43)}$, cardiac arrest ${ }^{(47)}$, and medications-related problems ${ }^{(49)}$. Outcomes such as anxiety, stress, and satisfaction of patients and families also appear in the studies $(24,28,30,44,48)$. 
In studies with qualitative approaches on readmissions(21) or post-discharge adverse events ${ }^{(11)}$, in the view of the care providers, factors related to the patient are listed, such as severity of the disease, undefined care goals, transfers at shift changes, nights or weekends, inadequate decision for discharge, professionals' lack of experience ${ }^{(11,21)}$, limited resources, lack of institutional policies ${ }^{(21)}$, staff sizing and inadequate monitoring in the IU, choosing the wrong destination for the patient and fragmenting care in several teams ${ }^{(11)}$. Suboptimal communication among team members, an inappropriate environment and atmosphere for efficient communication and the lack of communication of key information are also elements identified as possible causes of readmissions(21).

The association between the transition of care practices and the patients' outcomes has varied results when assessed in quantitative studies. Some studies verify the association of certain practices with readmission and mortality rates, such as discharges at nights or weekends(19,32,34-35). Discharges with delays of more than 24 hours showed a significant association with a higher incidence of delirium ${ }^{(40)}$. Medication reconciliation or pharmaceutical intervention by reviewing medications prior to patient transfer may contribute to a decrease in the number and severity of medication-related problems; however, the impact on the mortality rate, length of hospital stay or ICU readmission is still inconclusive ${ }^{(49)}$. Using a medical alert form for the most vulnerable patients with guidance to the IU team, in addition to improvements in oral communication, tended to reduce readmission rates and calls to the $\mathrm{RRT}^{(43)}$.

On the other hand, some studies that tried to evidence the efficiency of strategies (such as the adoption of ICU discharge criteria, anticipated discharge planning, availability of intermediate care units, medication reconciliation, oral and written communication about the transfer, optimization of patient monitoring post-ICU and instructions to IU nurses) did not achieve significant results in reducing bad outcomes such as readmission and mortality(13-14,39-40).

\section{Discussion}

The 37 studies were published uniformly over time, showing a demand for knowledge in the last five years. More than $50 \%$ was conducted in the United States, Canada, Australia and New Zealand, and the other studies were concentrated in Europe, with only two carried out in Asia and three in
Latin America (one in Brazil), which shows that the production of knowledge on the subject is concentrated in a few countries, possibly because it is a recent topic in the literature, which suggests the need for expansion and universalization to other regions that may present quite different aspects regarding the practices. A scoping review made in $2015^{(4)}$ also showed a concentration of most publications in the United States, Europe, and Australia. No other review was found in this format, which evaluates only adult patients.

According to the results identified, the transition of care in the discharge from intensive care is influenced by numerous components, whether intrinsic to the patient or related to the policies, practices or structure of the scenarios and professionals involved. Likewise, a previous study ${ }^{(4)}$ identified countless themes and factors related to professionals and the institution, which can act as facilitators or barriers to high quality care, confirming that being discharged from the ICU is a multifaceted and complex process.

With regard to factors related to the patient, conditions were identified that may predispose to worse outcomes after discharge from the ICU, especially conditions prior to discharge, such as the comorbidities and severity at the moment of hospitalization(11,19-21), older age ${ }^{(19-20)}$, altered state of consciousness, and greater need for supportive therapies(20). These findings are similar to other studies which identified that sicker patients, with greater severity at the moment of hospitalization ${ }^{(53)}$ and older patients ${ }^{(9)}$ had a greater chance of adverse events, readmission, and death after being discharged from intensive care. The altered state of consciousness was also found as a risk factor, along with polyneuropathy, myopathy and being discharged from the ICU using tube feeding, which often affect critically ill patients ${ }^{(53-54)}$.

Such factors are intrinsic to the patients, that is, they cannot be changed; therefore, they suggest the need to adopt specific strategies according to the profile and the individual demands of each patient, providing optimization and careful evaluation of the right moment for discharge, anticipated planning, more supervision for patients with greater severity, choice of the best destination unit or resizing of personnel and care for the most complex and dependent patients in the IU, in addition to stimulating greater family support, among other actions ${ }^{(11,23)}$.

Based on the 37 studies included, 30 practices, strategies and tools with a potential positive or negative impact were verified in the transition from the ICU to the IU, of which 21 were related to the ICU, seven were related to IU and two related to both. 
It is observed that most applies to the execution of the transfer, monitoring and care provided after the transfer, with a smaller portion representing actions taken in advance, such as planning individual needs, assessing readiness for discharge and preparing the people involved (team-patient-family).

A previous study ${ }^{(4)}$ also identified 30 factors related to the patient, professional or institution that can act as facilitators and barriers to highquality care during discharge from the ICU. The main themes identified were patient's and family's needs and experiences, availability of complete and accurate information about the discharge, education related to the discharge for patients and families, discharge planning, standardization of the discharge process and the results of the patient discharge, including adverse events, readmission to the ICU and death. Few articles focused on education for health professionals working at the destination unit, medication reconciliation, and patient autonomy. The results were categorized into four different phases of the discharge process, namely: assessment of the patient's readiness for discharge, discharge planning, discharge execution, and post-discharge follow-up ${ }^{(4)}$. Attention is drawn to studies that highlight the phase of discharge execution more than the other phases. In addition, actions focused on patient-centered care were commonly verified in studies with pediatric and neonatal patients, suggesting that there is a long way to go in the care of adult patients ${ }^{(4)}$.

It is noted that approximately half of the practices and strategies indicated by the studies can negatively influence the quality of the transitions. Among the main barriers are ineffective communication ${ }^{(21,23-25,27,36-38)}$, lack of planning, and choosing the inappropriate time for discharge, both from the point of view of time/ day of discharge and the patient's readiness to be discharged(11,14,19-22,24-25,27-28,30,32-35,37-38,42). The ideal conditions for patient discharge should consider, in addition to the clinical aspects, their level of dependence, the availability of family support, and the capacity of the destination unit/team to meet their demands ${ }^{(28,37)}$.

The choice of the inappropriate time for discharge is sometimes driven by pressure due to the demand for ICU beds or the lack of responsibility for continuity of care, in which professionals fragment the process and do not feel responsible for the patients' evolution after their transfer ${ }^{(28,38)}$. Survival after a critical illness is often associated with a long path and a potentially complicated recovery, which affects the quality of life of patients and their caregivers, and can persist for years after hospitalization ${ }^{(17)}$. On the other hand, delaying discharge from the ICU also brings unfavorable outcomes, such as inefficient use of hospital resources and delay in the hospitalization of other critical patients ${ }^{(8,11)}$.

The decision to discharge from the ICU cannot be taken separately and in a single moment, it must be discussed throughout the hospitalization to enable a better assessment of the best moment, the planning of the practices and strategies that best apply to each case, anticipating demands for physical and human resources and for preparation of the patient and family for an adequate continuity of care in the transition ${ }^{(25,29)}$. Therefore, the assessment for discharge must integrate daily discussions and use minimum criteria for a safe transfer, if possible, integrating risk stratification strategies to alert those involved and think about specific actions to prevent unfavorable outcomes.

Some studies suggest the use of scores to define patient readiness for discharge, such as the Stability and Workload Index for Transfer (SWIFT) (50) scale, which includes in the score the patient's original unit and length of stay in the ICU, the Glasgow Coma Scale (GCS), the ratio of partial arterial oxygen pressure $(\mathrm{PaO} 2) /$ inspired fraction of oxygen (IfO2) and arterial pressure of carbon dioxide (ApCO2). Other studies using risk scores to guide the decision to discharge ${ }^{(8,55)}$ include physiological, clinical and laboratory results measures like vital signs, clinical assessment, Braden scale scores, laboratory tests, and heart rate, jointly. Altered vital signs and level of consciousness at the moment of discharge are also suggested as predictors of risk for clinical deterioration in the IU independently(10,12), or composing a scale(56).

One of the main pillars for a quality transition of care is effective communication, as it permeates all moments and actors, so that several positive or negative aspects related may include oral and written communication, such as, for example, discharge summary and/or information transfer forms to the next caregiver. Several studies(21,23-25,27,36-38) revealed inadequate communication of key information and lack of standardization. Ineffective communication can be caused by many factors, such as different expectations between those who pass on and those who receive the information, cultural issues (absence of teamwork and lack of respect among professionals), inadequate time for this activity and lack of methods or standardized tools ${ }^{(57)}$.

Similarly to the findings of this review, in which strategies are suggested for improving communication, such as the use of standardized tools, face-to-face interaction with the professional to whom the patient 
is transferred, use of checklists, identification of the best time and place to transfer and inclusion of the patient and family(23-24,27), other studies confirm that the use of standardized tools, adequate environment and time, eye contact, and active listening are crucial factors in ensuring effective communication ${ }^{(57-58)}$.

The preparation and discharge guidelines for patients and their families were mentioned in several studies as a fundamental stage in the process $^{(22-24,28-29,42,44-45,48)}$; however, the best strategy is not yet established. Patients and family members are still often excluded from the transition of care process and the information provided is sometimes conflicting, diverging between professionals or teams, and unclear instructions on future care are offered, with technical terms and little time dedicated to this

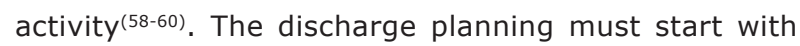
the information of the plan to the patient and the family members, allowing for the activation of support systems that may be necessary and guiding them on the care received, the planned care, the discharge process, and how the destination unit works ${ }^{(4)}$.

The medication review by a pharmacist before transferring the patient to the IU proved to be effective in reducing the number and severity of medicationsrelated problems ${ }^{(49)}$, although the impact on outcomes such as mortality and readmission is inconclusive ${ }^{(14,49)}$. A recent study ${ }^{(61)}$ found that medication reconciliation by a pharmacist reduced errors in medication transfer, potential adverse events, and related costs.

The choice of the destination can be a decisive factor in the patient's outcomes, as in the example of the availability of intermediate care units; however, its impact is still controversial, both in the analyzed articles $^{(14,50)}$, and also as noted by other authors ${ }^{(52,62)}$. In a study conducted in Brazil, referral to an intermediate care unit did not affect in-hospital mortality or the incidence of readmissions in the $\mathrm{ICU}^{(52)}$, while other study showed a significantly lower risk of readmission for patients transferred to an intermediate care unit(62).

The follow-up or guidance after discharge by members of the intensive care team is one of the strategies with a potential positive impact on the patients' outcomes, as evidenced by some studies, showing a decrease in the length of hospital stay(31) and in the ICU readmission rate ${ }^{(31,47)}$; however, there was no consensus ${ }^{(13-14)}$. Corroborating these findings, a meta-analysis carried out in 2014 identified that transition of care programs focused on the followup after discharge from the intensive care were associated with reduced risk of readmission to the ICU(6). The programs were developed by medical emergency teams or liaison nurses who did follow-up or offered consultations to patients after discharge from the ICU, but the team members did not always have prior contact with the patient before discharge. Thus, there is a need for more research to prove the real impact of the programs and services of follow-up after discharge from the ICU.

The readmission(13-14,20,26,31-32,34-35,43,46-47,49-52) and death $^{(13-14,19-20,31-35,39,43,46,49,51-52)}$ outcomes were more analyzed in the studies than other outcomes, with mortality rates showing a wide variation $(3-30 \%)^{(19,46)}$. Few studies were devoted to assessing other adverse outcomes; however, it is important to note that not all patients undergoing an inadequate transition process evolve to death or readmission but, even so, they may be subjected to unwanted repercussions with serious consequences, such as the need to change or increase the length of treatment, increased length of hospital stay, disabilities, increased hospital costs, and dissatisfaction ${ }^{(9)}$.

A recent study found that $21 \%$ of the discharged patients had post-ICU deterioration, including cardiac arrest, RRT calls, and readmission(63). Patients undergoing lung transplantation and other thoracic surgery, as well as advanced age, increased severity of the disease estimated by the Acute Physiology and Chronic Health Evaluation III (APACHE III) score, bradycardia, abnormal levels of albumin in the admission to the ICU, hyperkalemia and high level of activated partial thromboplastin time (APTT) at discharge from the ICU, presented a higher risk regardless of deterioration. In addition to these factors intrinsic to the patient, it was found that the patient being ready for discharge less than 48 hours before was an independent risk factor, which may indicate insufficient time for planning the transition of care ${ }^{(63)}$. A broader analysis of the adverse outcomes due to failures in the ICU discharge process is essential, considering its potential impact on outcomes that have an impact on the quality of life of the patients and their families.

The limitations of this scoping review include the fact that the authors delimited the published primary studies, that is, review studies and gray literature were not included, and that there were language restrictions. The heterogeneity of the studies analyzed, both in terms of methodology and diversity of outcomes and presentation, limits the comparison between the data. In addition, it is possible that a precise and exhaustive data extraction was not achieved, given the number and plurality of outcomes included, although it was performed by two reviewers, using a tool to systematically conduct data extraction. The classification of the impact of the 
practices, strategies or tools as positive or negative, although made independently by both reviewers with subsequent consensus, is relatively subjective since many studies do not report the outcomes clearly, hindering their interpretation.

A series of practices, strategies and tools were indicated to have a potential to assist in the coordination of the discharge process, improving the sometimes unfavorable outcomes of critical patients with complex care needs, even after leaving the intensive care environment. Such results reinforce the complexity of the ICU discharge process, in which many factors are involved and indicate critical points that can be improved in the transition of care, suggesting that the adoption of fragmented strategies, involving only a few phases, is likely to be unsuccessful.

In spite of that, the results of this review indicate that there is no consensus regarding the factors that influence transition of care after discharge from the ICU, the best practices or strategies that can be effective, or even regarding the repercussions and outcomes caused to the patient-family, which shows a wide range of themes to be explored in search of better scientific evidence on the subject. New studies should discuss the best strategies but should not be limited to a single practice, strategy or tool, as it is a complex process that needs to cover the several components and characters involved.

\section{Conclusion}

This review made it possible to identify components and to map the transition of care practices used in the discharge of adult patients from the ICU to the IU. Thirty practices, strategies and tools were used to organize and execute the transfer process. Some of the factors that stand out are related to the ICU and the hospitalization unit to which the patient was transferred, and cross-sectional to the units, to the teams involved and the institution itself, which may be associated with positive or negative outcomes. In addition, factors intrinsic to the patient, such as comorbidities and severity of the disease at the time of hospitalization, were associated with worse outcomes after discharge from the ICU.

Practices such as discharge at night or on weekends showed association with increased rates of readmission and mortality. Medication reviews by pharmacists and the adoption of warning systems for patients at risk in the IU showed a tendency to reduce adverse outcomes, such as drug-related problems, RRT calls and readmission. Other practices are recognized as potential predictors or protectors for outcomes after discharge from the ICU; however, there was no consensus in the literature.

Therefore, the association between transition of care and the outcome of the patient after transfer to the IU is still inconclusive, further research studies being necessary to assess the impact of different practices, strategies, and tools. There are also new research opportunities to evaluate the implementation of such practices, isolated and combined, in different scenarios of clinical practice, seeking to identify the effect on the quality of the intensive care discharge process.

In addition to the relevance in the field of research, this study offers contributions to professionals, patients and families, showing the need for a broader transition of care process, with reformulation of practices, considering the complexity involved since the patient's hospitalization in the ICU until the stabilization in the IU, for the quality of continuous care. The adoption of transition of care programs can be an effective management tool for health institutions, reducing the length of hospital stay and improving the use of resources.

\section{References}

1. The Joint Commission International. Joint Commission Resources. Transitions of Care: The need for a more effective approach to continuing patient care. [Internet]. 2012 Jun [cited Jul 3, 2018]. Available from: https://www.jointcommission.org/assets/1/18/ Hot_Topics_Transitions_of_Care.pdf

2. World Health Organization. Transitions of Care: Technical Series on Safer Primary Care. [Internet]. Geneva: World Health Organization; 2016 [cited Jul 6, 2017]. Available from: https://apps.who.int/iris/ bitstream/handle/10665/252272/9789241511599eng.pdf;jsessionid=F02F4867BC0581E4B21DE72B23 FC0994? sequence $=1$

3. Rede Brasileira de Enfermagem e Segurança do Paciente. Estratégias para a segurança do paciente: manual para profissionais da saúde. [Internet]. Porto Alegre: EDIPUCRS; 2013 [Acesso 14 jul 2017]. Disponível em: http://biblioteca.cofen.gov.br/ wp-content/uploads/2017/10/Estrat\%C3\%A9giaspara-seguran\%C3\%A7a-do-paciente-manual-paraprofissionais-da-sa\%C3\%BAde.pdf

4. Stelfox HT, Lane D, Boyd JM, Taylor S, Perrier L, Straus $S$, et al. A scoping review of patient discharge from intensive care: opportunities and tools to improve care. Chest. 2015 Feb;147(2):317-27. doi: 10.1378/ chest.13-2965 
5. Guest M. Patient transfer from the intensive care unit to a general ward. Nurs Stand. 2017 Nov 1;32(10):4551. doi: 10.7748/ns.2017.e10670

6. Niven DJ, Bastos JF, Stelfox HT. Critical care transition programs and the risk of readmission or death after discharge from an ICU: a systematic review and metaanalysis. Crit Care Med. 2014 Jan;42(1):179-87. doi: 10.1097/CCM.0b013e3182a272c0

7. van Sluisveld N, Hesselink G, van der Hoeven JG, Westert G, Wollersheim H, Zegers M. Improving clinical handover between intensive care unit and general ward professionals at intensive care unit discharge. Intensive Care Med. 2015 Apr;41(4):589-604. doi: 10.1007/s00134-015-3666-8

8. Gotur DB, Masud F, Paranilam J, Zimmerman JL. Analysis of Rothman Index Data to Predict Postdischarge Adverse Events in a Medical Intensive Care Unit. J Intensive Care Med. 2018 May 2:1-5. doi: 10.1177/0885066618770128

9. Williams TA, Leslie GD, Elliott N, Brearley L, Dobb GJ. Introduction of discharge plan to reduce adverse events within 72 hours of discharge from the ICU. J Nurs Care Qual. 2010 Jan-Mar;25(1):73-9. doi: 10.1097/NCQ.0b013e3181b0e490

10. Chaboyer BW, Thalib L, Foster M, Ball C, Richards B. Predictors of adverse events in patients after discharge from the intensive care unit. Am J Crit Care. [Internet]. 2008 May [cited Jul 9, 2017];17(3):255-64. Available from: http://ajcc.aacnjournals.org/content/17/3/255. full.pdf+html

11. Elliott M, Page K, Worrall-Carter L. Factors associated with post-intensive care unit adverse events: a clinical validation study. Nurs Crit Care. 2014 Sep;19(5):228-35. doi: 10.1111/nicc.12091

12. Jo YS, Lee YJ, Park JS, Yoon II H, Lee JH, Lee C-T, et al. Readmission to medical intensive care units: risk factors and prediction. Yonsei Med J. 2015 Mar 1;56(2):543-9. doi: 10.3349/ymj.2015.56.2.543

13. Stelfox HT, Bastos J, Niven DJ, Bagshaw SM, Turin TC, Gao S. Critical care transition programs and the risk of readmission or death after discharge from ICU. Intensive Care Med. 2016 Mar;42(3):401-10. doi: 10.1007/s00134-015-4173-7

14. van Sluisveld N, Bakhshi-Raiez F, de Keizer N, Holman $\mathrm{R}$, Wester $\mathrm{G}$, Wollersheim $\mathrm{H}$, et al. Variation in rates of ICU readmissions and post-ICU in-hospital mortality and their association with ICU discharge practices. BMC Health Serv Res. 2017 Apr 17;17(281):1-9. doi: 10.1186/s12913-017-2234-z
15. Lin F, Chaboyer W, Wallis M. A literature review of organisational, individual and teamwork factors contributing to the ICU discharge process. Aust Crit Care. 2009 Feb;22(1):29-43. doi: 10.1016/j. aucc.2008.11.001

16. Peters MDJ, Godfrey CM, Khalil H, McInerney P, Parker D, Soares CB. Guidance for conducting systematic scoping reviews. Int J Evid Based Healthc. 2015 Sep;13(3):141-6. doi: 10.1097/ XEB. 0000000000000050

17. Peters M, Godfrey CM, Mcinerney P, Baldini Soares C, Khalil H, Parker D. Scoping Reviews. In: Aromataris E, Munn Z, eds. Joanna Briggs Institute Reviewer's Manual. [Internet]. 2017 [cited May 24, 2019]. Available from: https://wiki.joannabriggs.org/display/ MANUAL/Chapter+11\%3A+Scoping+reviews

18. Moher D, Liberati A, Tetzlaff J, Altman DG. Preferred reporting items for systematic reviews and metaanalyses: the PRISMA statement. PLoS Med. 2009 Jul 21;6(7):1-6. doi: 10.1371/journal.pmed.1000097 19. Moreira $H E$, Verga $F$, Barbato M, Burghi G. Prognostic impact of the time of admission and discharge from the intensive care unit. Rev Bras Ter Intensiva. 2017 Mar;29(1):63-9. doi: 10.5935/0103507x.20170010

20. Santamaria JD, Duke GJ, Pilcher DV, Cooper DJ, Moran J, Bellomo R. Readmissions to intensive care: a prospective multicenter study in Australia and New Zealand. Crit Care Med. 2017 Feb;45(2):290-7. doi: 10.1097/CCM.0000000000002066

21. Ofoma UR, Dong Y, Gajic O, Pickering BW. A qualitative exploration of the discharge process and factors predisposing to readmissions to the intensive care unit. BMC Health Serv Res. 2018 Jan 5;18(6): 1-9. doi: 10.1186/s12913-017-2821-z

22. Li P, Boyd JM, Ghali WA, Stelfox HT. Stakeholder views regarding patient discharge from intensive care: suboptimal quality and opportunities for improvement. Can Respir J. 2015 Mar-Apr;22(2):109-18. doi: $10.1155 / 2015 / 457431$

23. Graan SM, Botti M, Wood B, Redley B. Nursing handover from ICU to cardiac ward: standardised tools to reduce safety risks. Aust Crit Care. 2016 Aug;29(3):165-71. doi: 10.1016/j.aucc.2015.09.002 24. Stelfox HT, Leigh JP, Dodek PM, Turgeon AF, Forster $A J$, Lamontagne $F$, et al. A multi-center prospective cohort study of patient transfers from the intensive care unit to the hospital ward. Intensive Care Med. 2017 Oct;43(10):1485-94. doi: 10.1007/s00134-0174910-1 
25. van Sluisveld $N$, Oerlemans A, Westert G, van der Hoeven JG, Wollersheim Hub, Zegers M. Barriers and facilitators to improve safety and efficiency of the ICU discharge process: a mixed methods study. BMC Health Serv Res. 2017 Apr 4;17(251):1-12. doi: 10.1186/s12913-017-2139-x

26. Coon EA, Kramer NM, Fabris RR, Burkholder DB, Klaas JP, Graff-Radford J, et al. Structured handoff checklists improve clinical measures in patients discharged from the neurointensive care unit. Neurol Clin Pract. 2015 Feb;5(1):42-9. doi: 10.1212/ CPJ.0000000000000094

27. de Grood C, Leigh JP, Bagshaw SM, Dodek PM, Fowler RA, Forster $A J$, et al. Patient, family and provider experiences with transfers from intensive care unit to hospital ward: a multicentre qualitative study. CMAJ. 2018 Jun 4;190(22):669-76. doi: 10.1503/cmaj. 170588

28. Cognet S, Coyer F. Discharge practices for the intensive care patient: a qualitative exploration in the general ward setting. Intensive Crit Care Nurs. 2014 Oct;30(5):292-300. doi: 10.1016/j.iccn.2014.04.004 29. Häggström M, Bäckström B. Organizing safe transitions from Intensive Care. Nurs Res Pract. 2014 Mar 24;2014:1-11. doi: 10.1155/2014/175314

30. Häggström M, Fjellner C, Öhman M, Holmström MR. Ward visits- one essential step in intensive care follow-up. An interview study with critical care nurses' and ward nurses'. Intensive Crit Care Nurs. 2018 Dec;49:21-7. doi: 10.1016/j.iccn.2018.08.011

31. Kheir F, Shawwa K, Nguyen D, Alraiyes AH, Simeone F, Nielsen ND. A 24-hour Postintensive Care Unit transition-of-care model shortens hospital stay. J Intensive Care Med. 2016 Oct 1;31(9):597-602. doi: 10.1177/0885066615569701

32. Azevedo LCP, de Souza IA, Zygun DA, Stelfox HT, Bagshaw SM. Association between nighttime discharge from the Intensive Care Unit and hospital mortality: a multi-center retrospective cohort study. BMC Health Serv Res. 2015 Sep 14;15(378):1-9. doi: 10.1186/ s12913-015-1044-4

33. Santamaria JD, Duke GJ, Pilcher DV, Cooper DJ, Moran J, Bellomo R, et al. The timing of discharge from the intensive care unit and subsequent mortality. A prospective, multicenter study. Am J Respir Crit Care Med. 2015 May 1;191(9):1033-9. doi: 10.1164/ rccm.201412-22080C

34. Wood SD, Coster S, Norman I. Comparing the monitoring of patients transferred from a critical care unit to hospital wards at after-hours with day transfers: an exploratory, prospective cohort study. ] Adv Nurs. 2014 Dec;70(12):2757-66. doi: 10.1111/ jan. 12410

35. Gantner D, Farley K, Bailey M, Huckson S, Hicks $\mathrm{P}$, Pilcher D. Mortality related to after-hours discharge from intensive care in Australia and New Zealand, 20052012. Intensive Care Med. 2014 Oct;40(10):1528-35. doi: $10.1007 /$ s00134-014-3438-x

36. Brown KN, Leigh JP, Kamran H, Bagshaw SM, Fowler RA, Dodek PM, et al. Transfers from intensive care unit to hospital ward: a multicentre textual analysis of physician progress notes. Crit Care. 2018 Jan 28;22(19): 1-8. doi: 10.1186/s13054-018-1941-0 37. Enger R, Andershed B. Nurses' experience of the transfer of ICU patients to general wards: a great responsibility and a huge challenge. J Clin Nurs. 2018 Jan;27(1-2):e186-94. doi 10.1111/jocn.13911

38. Rosenberg A, Britton MC, Feder S, Minges $K$, Hodshon B, Chaudhry SI, et al. A taxonomy and cultural analysis of intra-hospital patient transfers. Res Nurs Health. 2018 Aug;41(4):378-88. doi: 10.1002/ nur. 21875

39. Bose S, Johnson AEW, Moskowitz A, Celi LA, Raffa JD. Impact of intensive care unit discharge delays on patient outcomes: a retrospective cohort study. J Intensive Care Med. 2019 Nov 1;34(11-12):1-6. doi: $10.1177 / 0885066618800276$

40. Tiruvoipati R, Botha J, Fletcher J, Gangopadhyay $\mathrm{H}$, Majumdar M, Vij S, et al. Intensive care discharge delay is associated with increased hospital length of stay: a multicentre prospective observational study. PLoS One. 2017 Jul 27;12(7):1-13. doi: 10.1371/ journal.pone. 0181827

41. Boyd JM, Roberts DJ, Leigh JP, Stelfox HT. Administrator perspectives on ICU-to-ward transfers and content contained in existing transfer tools: a cross-sectional survey. J Gen Intern Med. 2018 Oct;33(10):1738-45. doi: 10.1007/s11606-0184590-8

42. Häggström M, Asplund $K$, Kristiansen L. Important quality aspects in the transfer process. Int $\mathrm{J}$ Health Care Qual Assur. 2014 Mar 3;27(2):123-39. doi: 10.1108/IJHCQA-09-2012-0090

43. Hoffman RL, Saucier J, Dasani S, Collins T, Holena DN, Fitzpatrick M, et al. Development and implementation of a risk identification tool to facilitate critical care transitions for high-risk surgical patients. Int J Qual Heal Care. 2017 Jun;29(3):412-9. doi: 10.1093/intqhc/mzx032 
44. Yun SH, Oh EG, Yoo YS, Kim SS, Jang YS. Development and Effects of a Transition Nursing Program for Patients and Family Caregivers at a Neurological ICU in Korea. Clin Nurs Res. 2017 Jan 1;26(1):27-46. doi: 10.1177/1054773815616973

45. Bench SD, Heelas K, White C, Griffiths P. Providing critical care patients with a personalised discharge summary: a questionnaire survey and retrospective analysis exploring feasibility and effectiveness. Intensive Crit Care Nurs. 2014 Apr;30(2):69-76. doi: 10.1016/j.iccn.2013.08.007

46. Alberto L, Zotárez $H$, Cañete TA, Niklas JEB, Enriquez JM, Gerónimo MR, et al. A description of the ICU liaison nurse role in Argentina. Intensive Crit Care Nurs . 2014 Feb;30(1):31-7. doi: 10.1016/j. iccn.2013.07.001

47. Choi S, Lee J, Shin Y, Lee J, Jung J, Han M, et al. Effects of a medical emergency team follow-up programme on patients discharged from the medical intensive care unit to the general ward: a single-centre experience. J Eval Clin Pract. 2016 Jun;22(3):356-62. doi: $10.1111 /$ jep. 12485

48. Bench S, Day T, Heelas K, Hopkins P, White C, Griffiths $P$. Evaluating the feasibility and effectiveness of a critical care discharge information pack for patients and their families: a pilot cluster randomised controlled trial. BMJ Open. 2015 Nov;5(11):1-11. doi: 10.1136/bmjopen-2014-006852

49. Heselmans A, van Krieken J, Cootjans S, Nagels K, Filliers, Dillen $K$, et al. Medication review by a clinical pharmacist at the transfer point from ICU to ward: a randomized controlled trial. J Clin Pharm Ther. 2015 Out;40(5):578-83. doi: 10.1111/jcpt.1231410.1111/ jcpt. 12314

50. Ofoma UR, Chandra S, Kashyap R, Herasevich $V$, Ahmed A, Gajic $O$, et al. Findings from the implementation of a validated readmission predictive tool in the discharge workflow of a medical intensive care unit. Ann Am Thorac Soc. 2014 Jun 1;11(5):73743. doi: 10.1513/AnnalsATS.201312-4360C

51. Al-Jaghbeer MJ, Tekwani SS, Gunn SR, Kahn JM. Incidence and etiology of potentially preventable ICU readmissions. Crit Care Med. 2016 Sep;44(9):1704-9. doi: 10.1097/CCM.0000000000001746

52. Correa TD, Ponzoni CR, Rabelo R Filho, Serpa A Neto, Chaves RCF, Pardini A, et al. Nighttime intensive care unit discharge and outcomes: a propensity matched retrospective cohort study. PLoS One. 2018 Dec 13;13(12):1-13. doi: 10.1371/journal. pone. 0207268
53. Katsiari M, Ntorlis K, Mathas C, Nikolaou C. Predictors of Adverse Outcome Early After ICU Discharge. Int J Crit Care Emerg Med. 2018 Jan 7;5(1):1-6. doi: 10.23937/2474-3674/1510065

54. Araujo TG, Rieder MM, Kutchak FM, Franco JW Filho. Readmissions and deaths following ICU discharge: a challenge for intensive care. Rev Bras Ter Intensiva. 2013 Mar 1;25(1):32-8. doi: 10.1590/ S0103-507X2013000100007

55. Piper GL, Kaplan LJ, Maung AA, Lui FY, Barre K, Davis KA. Using the Rothman index to predict early unplanned surgical intensive care unit readmissions. J Trauma Acute Care Surg. 2014 Jul;77(1):78-82. doi: 10.1097/TA.0000000000000265

56. Uppanisakorn S, Bhurayanontachai R, Boonyarat J, Kaewpradit J. National Early Warning Score (NEWS) at ICU discharge can predict early clinical deterioration after ICU transfer. J Crit Care. 2018 Feb;43:225-9. doi: 10.1016/j.jcrc.2017.09.008

57. Benham-Hutchins MM, Effken JA. Multi-professional patterns and methods of communication during patient handoffs. Int J Med Inform. 2010 Apr;79(4):252-67. doi: 10.1016/j.ijmedinf.2009.12.005

58. Alves M, Melo CL. Transferência de cuidado na perspectiva de profissionais de enfermagem de um pronto-socorro. Rev Min Enferm. 2019;23:e-1194. doi: 10.5935/1415-2762.20190042

59. Burke RE, Kripalani S, Vasilevskis EE, Schnipper JL. Moving beyond readmission penalties: creating an ideal process to improve transitional care. J Hosp Med. 2013 Feb;8(2):102-9. doi: 10.1002/jhm.1990

60. Snow V, Beck D, Budnitz T, Miller DC, Potter J, Wears RL, et al. Transitions of Care Consensus Policy Statement American College of Physicians-Society of General Internal Medicine-Society of Hospital Medicine-American Geriatrics Society-American College of Emergency Physicians-Society of Academic Emergency Medicine. J Gen Intern Med. 2009 Aug;24(8): 971-6. doi: 10.1007/s11606-009-0969-x 61. Bosma LBE, Hunfeld NGM, Quax RAM, Meuwese E, Melief PHGJ, van Bommel J, et al. The effect of a medication reconciliation program in two intensive care units in the Netherlands: a prospective intervention study with a before and after design. Ann Intensive Care. 2018 Feb 7;8(19):1-13. doi: 10.1186/s13613018-0361-2

62. Badawi O, Breslow MJ. Readmissions and death after ICU discharge: development and validation of two predictive models. PLoS One. 2012 Nov 7;7(11):1-15. doi: 10.1371/journal.pone. 0048758 
63. Ng YH, Pilcher DV, Bailey M, Bain CA, MacManus C, Bucknall TK. Predicting medical emergency team calls, cardiac arrest calls and re-admission after intensive care discharge: creation of a tool to identify at-risk patients. Anaesth Intensive Care. 2018;46(1):88-96.

doi: $10.1177 / 0310057 \times 1804600113$ Creative Commons (CC BY).

This license lets others distribute, remix, tweak, and build upon

your work, even commercially, as long as they credit you for the original creation. This is the most accommodating of licenses 